\title{
Precipitable water observed by ground-based GPS receivers and microwave radiometry
}

\author{
Yuei-An Liou, Cheng-Yung Huang, and Yu-Tun Teng \\ Center for Space and Remote Sensing Research, and Institute of Space Sciences National Central University, Chungli, Taiwan
}

(Received September 20, 1999; Revised January 20, 2000; Accepted May 11, 2000)

\begin{abstract}
The sensing of absolute precipitable water vapor (PW) by the Global Positioning System (GPS) and a Water Vapor Radiometer (WVR) is presented. The GPS approach requires a priori knowledge of the relationship between the weighted mean temperature of the atmosphere and surface temperature whose regression relationship is derived based on ten-year climatological data observed by radiosonde and surface meteorological instruments. Similarly, the WVR scheme needs a priori information of the relationship between sky brightness temperature and PW whose regression relationship is characterized based on the same set of climatological data. GPS-derived PW are compared with those observed by WVR and radiosondes. The GPS and WVR data were collected at the Taipei weather station of Taiwan Central Weather Bureau (CWB) from March 18 to 24, 1998. To obtain the estimates of absolute PW at the Taipei site, GPS data acquired from Tsukuba, Japan, at a distance of $2155 \mathrm{~km}$ from Taipei were utilized. It is found that GPS-derived PW agrees reasonably well with observations by the WVR and radiosondes. The average of GPS-derived PW is $3.38 \mathrm{~cm}$ with a standard deviation of $0.39 \mathrm{~cm}$. The difference between the average GPS-derived and WVR-observed PW is $0.27 \mathrm{~cm}$ with a bias of $-0.04 \mathrm{~cm}$, while the difference between the average GPS-derived and radiosonde-observed PW is somewhat larger, $0.36 \mathrm{~cm}$ with a bias of $-0.42 \mathrm{~cm}$. These differences are larger than differences reported at higher latitudes in regions with lower average humidity.
\end{abstract}

\section{Introduction}

Atmospheric water vapor is extremely variable in both spatial and temporal domains, while it is a key parameter in weather and climate modeling and prediction. It is hence one of the major atmospheric constituents that must be carefully monitored for atmospheric modeling and prediction.

Precipitable water vapor (PW) can be derived from groundbased GPS data. Rocken et al. (1993) demonstrated groundbased GPS sensing of PW with 1-2 mm accuracy. The retrieved PW data were verified by comparison with WVRs. Businger et al. (1996) summarized the use of ground-based GPS receivers to retrieve $\mathrm{PW}$. The retrieved PW data were verified by observations of WVR and radiosonde data. Ware et al. (1997) showed the sensing of integrated water vapor along GPS paths. Liou and Yang (1999) presented GPS sensing of absolute PW by using radiometer-observed wet delay to constrain one end of a 114-km baseline. It was suggested that a minimum baseline of $500 \mathrm{~km}$ is required in order to derive absolute path delay of the GPS signals through the troposphere (Rocken et al., 1993; Duan et al., 1996). On the other hand, Tregoning et al. (1998) indicated that a baseline of $2000 \mathrm{~km}$ is needed to decorrelate the tropospheric effects on the two ends of the baseline.

In this paper, we further our previous work (Liou and Yang, 1999) to calculate absolute wet path delay of the GPS signals through the troposphere. GPS data were acquired at Taipei and Tsukuba, Japan, from March 18 to 24, 1998. The

Copy right $(\mathrm{C}$ The Society of Geomagnetism and Earth, Planetary and Space Sciences (SGEPSS); The Seismological Society of Japan; The Volcanological Society of Japan; The Geodetic Society of Japan; The Japanese Society for Planetary Sciences. baseline between the two sites is $2155 \mathrm{~km}$. Ground-based GPS sensing of PW generally includes three major steps: 1) Compute the excess microwave propagation path, 2) Derive the wet delay, and 3) Map the wet delay onto water vapor. Since the first two steps have been well presented in the literature, they are not discussed in the current presentation for simplicity.

\section{Map ZWD onto PW}

Radio signals transmitted from the GPS satellites are delayed by the atmosphere before they are received on the ground. The delay due to the presence of water vapor in the troposphere offers an opportunity to observe PW using ground-based GPS. Bernese GPS software version 4.0 developed by the University of Berne (Beutler et al., 1996) was utilized to solve the GPS observables of carrier phase for the excess Optical Path Length (OPL). Zenith wet delay (ZWD) was subsequently derived by subtracting the zenith hydrostatic delay (ZHD) from the excess OPL.

PW can be derived form zenith wet delay (ZWD) by Bevis et al. (1994)

$$
\mathrm{PW}=\Pi \times \mathrm{ZWD}
$$

where

$$
\Pi=\frac{10^{8}}{\rho R_{\mathrm{v}}\left[\left(k_{3} / T_{\mathrm{m}}\right)+k_{2}^{\prime}\right]},
$$

and $\rho$ is the density of water $\left(\mathrm{kg} / \mathrm{m}^{3}\right), R_{\mathrm{v}}$ is the specific gas constant of water vapor $(\mathrm{J} / \mathrm{kg}-\mathrm{K}), k_{2}^{\prime}$ is $22.1 \pm 2.2(\mathrm{~K} / \mathrm{mb}), k_{3}$ is $(3.739 \pm 0.012) \times 10^{5}\left(\mathrm{~K}^{2} / \mathrm{mb}\right), T_{\mathrm{m}}$ is the weighted mean 
Table 1. Radiosonde observations of $\Pi$.

\begin{tabular}{ccc}
\hline Month & Mean & Standard Deviation \\
\hline Jan & 0.160 & 0.0016 \\
Feb & 0.160 & 0.0017 \\
Mar & 0.161 & 0.0021 \\
Apr & 0.163 & 0.0018 \\
May & 0.164 & 0.0014 \\
Jun & 0.166 & 0.0012 \\
Jul & 0.167 & 0.0010 \\
Aug & 0.167 & 0.0009 \\
Sep & 0.165 & 0.0013 \\
Oct & 0.164 & 0.0016 \\
Nov & 0.163 & 0.0019 \\
Dec & 0.161 & 0.0016 \\
\hline
\end{tabular}

temperature of the atmosphere $(\mathrm{K})$,

$$
T_{\mathrm{m}}=\frac{\int\left(P_{\mathrm{v}} / T\right) d z}{\int\left(P_{\mathrm{v}} / T^{2}\right) d z},
$$

where $P_{\mathrm{v}}$ is the pressure of water vapor $(\mathrm{mb})$, and $T$ is the temperature of the atmosphere $(\mathrm{K})$. In general, $\Pi$ is about 0.15 , while it is a function of season, location, and weather. Its amplitude may scatter over a range of $20 \%$ (Bevis et al., 1994). Hence, we examine the variablity of $\Pi$ based on tenyear radiosonde collected at CWB's Taipei weather station from the year 1988 to 1997 . Table 1 shows the mean values and standard deviations of $\Pi$ for twelve months. An expected dependence of $\Pi$ on season is observable. Since the period of interest in the current study is March, the results from March were used to reduce the uncertainty caused by seasonal effects. The total number of radiosonde observations is 586 for March during the ten years, with $\Pi$ ranging from 0.15 to 0.17 with an average value of 0.16 and a standard deviation of 0.002 .

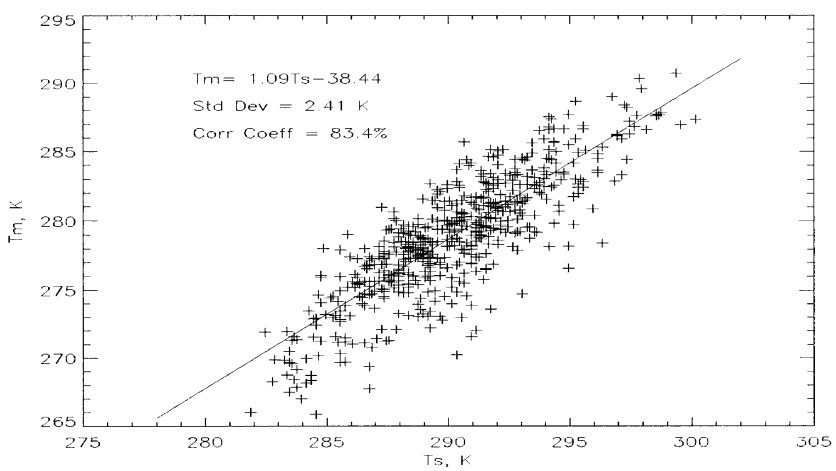

Fig. 1. Weighted mean temperature $\left(T_{\mathrm{m}}\right)$ versus surface temperature $\left(T_{\mathrm{s}}\right)$ at the Taipei weather station every March from 1988 to 1997.
Table 2. Regression relationship between $T_{\mathrm{m}}$ and $T_{\mathrm{s}}\left(T_{\mathrm{m}}=a T_{\mathrm{s}}+b\right)$, and rms deviation (rmsd) about the regression.

\begin{tabular}{ccrc}
\hline Month & $\mathrm{a}$ & \multicolumn{1}{c}{$\mathrm{b}$} & rmsd, K \\
\hline Jan & 0.95 & 3.5 & 2.68 \\
Feb & 0.98 & -5.6 & 2.52 \\
Mar & 1.09 & -38.4 & 2.41 \\
Apr & 0.92 & 12.1 & 2.90 \\
May & 0.85 & 32.1 & 2.73 \\
Jun & 0.86 & 27.6 & 2.90 \\
Jul & 0.90 & 16.3 & 2.68 \\
Aug & 0.92 & 9.7 & 2.69 \\
Sep & 0.99 & -9.4 & 2.73 \\
Oct & 0.99 & -9.7 & 2.17 \\
Nov & 1.12 & -48.6 & 2.46 \\
Dec & 0.97 & -4.2 & 2.30 \\
\hline
\end{tabular}

GPS measurements can be taken as frequently as once per second with the GPS receivers currently deployed in Taiwan. However, calculation of $T_{\mathrm{m}}$ is limited to twice per day by the frequency of radiosonde data. Bevis et al. (1992) suggested that $T_{\mathrm{m}}$ can be approximated by the surface temperature $T_{\mathrm{s}}$. Figure 1 shows $T_{\mathrm{m}}$ versus $T_{\mathrm{s}}$ observed at the Taipei site each March from the year 1988 to 1997 . The correlation coefficient between $T_{\mathrm{m}}$ and $T_{\mathrm{s}}$ reaches as high as $83.4 \%$ which allows the relationship between $T_{\mathrm{m}}$ and $T_{\mathrm{s}}$ to be determined by minimizing the Chi-square error statistic as

$$
T_{\mathrm{m}}=1.09 T_{\mathrm{s}}-38.4 \text {. }
$$

The root mean square (rms) deviation about this regression is $2.41 \mathrm{~K}$. Equation (4) differs from $T_{\mathrm{m}}=0.72 T_{\mathrm{s}}+70.2$ with a corresponding rms deviation of $4.74 \mathrm{~K}$ (Bevis et al., 1992). The relationship between $T_{\mathrm{m}}$ and $T_{\mathrm{s}}$ for the other months of the year, found by minimizing the Chi-square error statistic, is given in Table 2. The rms deviations about the regression are also listed in Table 2. Seasonal dependence of the relationship between $T_{\mathrm{m}}$ and $T_{\mathrm{s}}$ is obvious.

Through Eqs. (2) and (4), $T_{\mathrm{s}}$ can be used to derive $\Pi$, which is found to have a mean value of 0.161 with a standard deviation of 0.0021 for the 10-year March radiosonde data set. This approach provides an estimate of $\Pi$ with a precision of $0.85 \%$, with a positive bias of 0.0024 . This bias results from a trend in the value of $\Pi$ over ten years. This trend may caused by climate or urban development effects in the radiosonde and surface met data. We are studying these trends and will report our findings separately. In order to compensate for the effect of this trend, a downshifting by 0.0024 is appropriate if $T_{\mathrm{s}}$ is used to derive $\Pi$ (denoted by $\hat{\Pi})$. The precision of this approach in deriving $\Pi$ remains the same if a down-shifting is performed. Figure 2 shows differences between $\Pi$ and $\hat{\Pi}$. The differences generally fall onto or near the $\Pi-\hat{\Pi}=0$ line. Figure 3 shows the corresponding $\Pi$ and $T_{\mathrm{s}}$. The signatures of $\Pi$ and $T_{\mathrm{s}}$ exhibit 


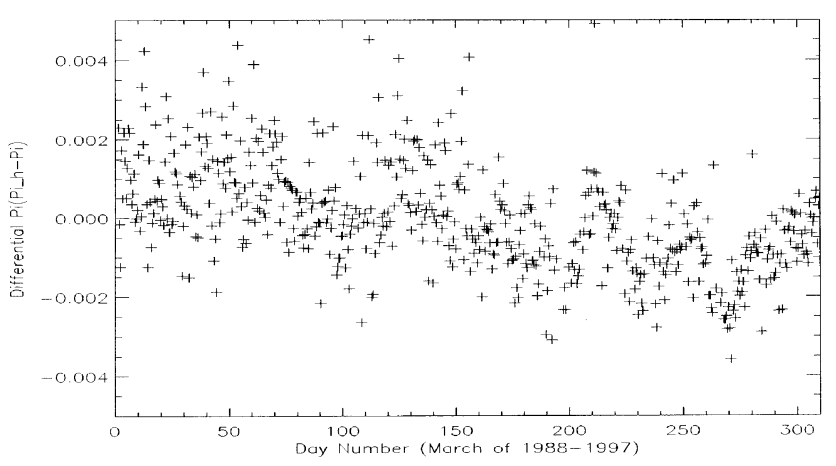

Fig. 2. Difference between $\Pi(=\mathrm{PW} / \mathrm{ZWD})$ and $\hat{\Pi}$ at the Taipei weather station every March from 1988 to 1997.

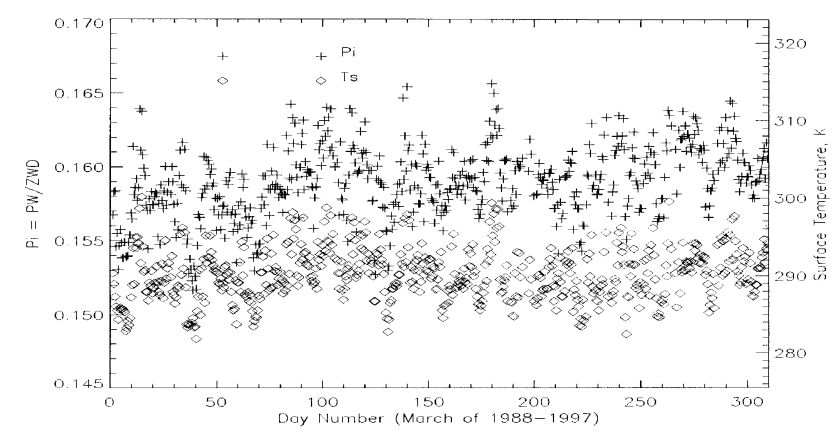

Fig. 3. П (Pi) derived from radiosonde data and surface temperature at the Taipei weather station every March from 1988 to 1997.

an expected high correlation since the former is derived from a linear regression of the latter.

\section{Radiometric Sensing of ZWD and PW}

Radiometric sensing of PW is a typical approach to validate the GPS scheme. It is based upon radiative transfer theory

$$
T_{\mathrm{b}}=T_{\mathrm{bc}} e^{-\tau(0, \infty)}+\int_{0}^{\infty} \kappa_{e}(r) T_{\mathrm{a}}(r) e^{-\tau(0, r)} d r,
$$

where $T_{\mathrm{b}}$ is the brightness temperature observed by a groundbased radiometer $(\mathrm{K}), T_{\mathrm{bc}}$ is the cosmic brightness temperature $(\mathrm{K}), \tau(0, r)$ represents the optical depth between the radiometer and position $r$ (nepers), and $\kappa_{e}$ is the extinction coefficient of the atmosphere $(\mathrm{dB} / \mathrm{km})$. Major contributions to $\tau$ include oxygen, water vapor, and suspended water droplets (if present). Since the upper limit for cloud droplet radii in the earth's atmosphere is around $0.1 \mathrm{~mm}$ (Bean and Dutton, 1968), absorption in liquid water cloud regions exceeds scattering by at least two orders of magnitude (Janssen, 1993). It is expected that ignoring scattering in Eq. (5) causes errors of less than $1 \%$ in the frequency regime of concern so that the extinction coefficient can be comfortably replaced by the absorption coefficient. Nevertheless, scattering effects should be carefully handled when liquid water particle sizes of rainfall approach the wavelength at the frequency of interest. For the purpose of the current presentation, scattering does not make a significant contribution to the observations from the radiometer since the data were primarily taken during no rain periods.
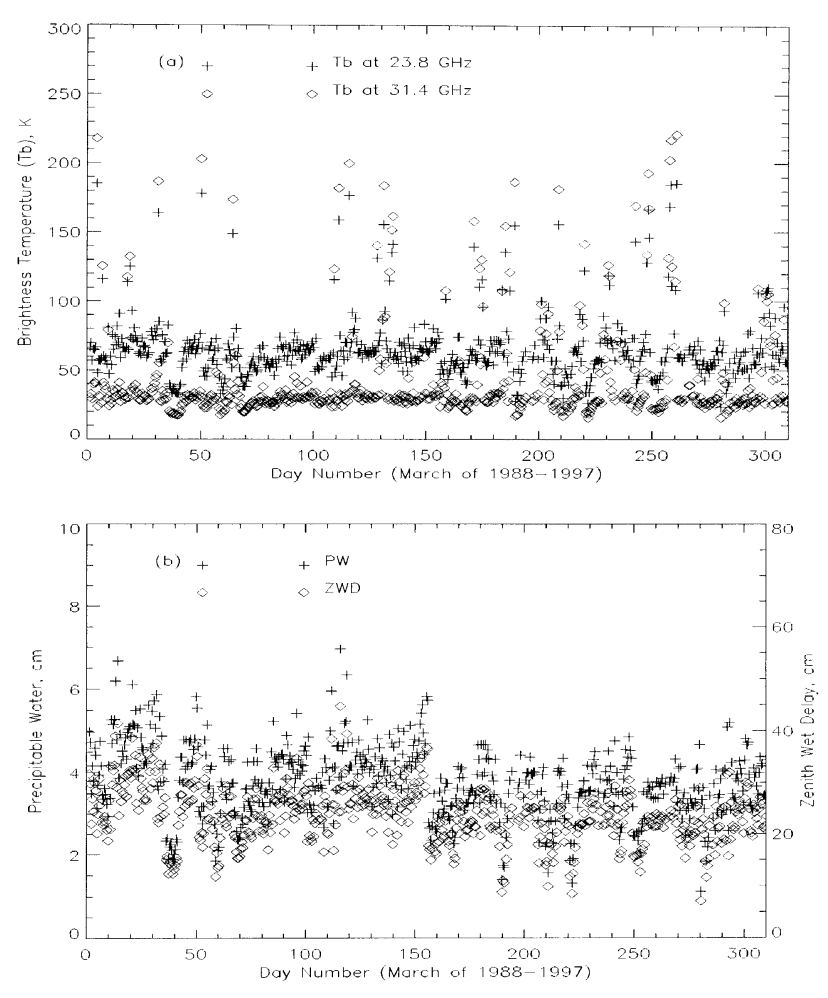

Fig. 4. (a) Atmospheric brightness temperatures at 23.8 and $31.4 \mathrm{GHz}$ derived from the radiosonde soundings collected in each March from the year 1988 to 1997 (Liou, 1999a), and (b) the corresponding PW and ZWD.

Equations (1) and (5) reveal that PW and ZWD can be determined from radiometric signatures of the atmosphere. That is, for a dual-channel, ground-based radiometer observation, ZWD and PW can be determined by bilinear regressions (Liou, 1999a and b)

$$
\begin{aligned}
\mathrm{ZWD} & =C_{\mathrm{ZWD} 0}+C_{\mathrm{ZWD} 1} \times T_{\mathrm{b} 1}+C_{\mathrm{ZWD} 2} \times T_{\mathrm{b} 2}, \\
\mathrm{PW} & =C_{\mathrm{PW} 0}+C_{\mathrm{PW} 1} \times T_{\mathrm{b} 1}+C_{\mathrm{PW} 2} \times T_{\mathrm{b} 2},
\end{aligned}
$$

respectively, where $C_{i}$ are the regression coefficients with subscript $i$ representing ZWD0, ZWD1, ZWD2, PW0, PW1, and PW2, and $T_{\mathrm{bi}}$ are the observed brightness temperatures of the atmosphere $(\mathrm{K})$, with subscript $i=1$ and 2 representing the two frequencies of 23.8 and $31.4 \mathrm{GHz}$ of interest, respectively. To obtain the regression coefficients, ten-year radiosonde soundings collected at CWB's Taipei weather station from the year 1988 to 1997 were used to characterize the atmospheric state. Brightness temperature of the atmosphere at the two frequencies of concern are determined based on the radiative transfer model proposed by Liebe (1989). Profiles of water vapor, temperature, and pressure of the atmosphere are interpolated to $0.1 \mathrm{mb}$ in the determination of sky brightness temperature.

Figure 4 shows (a) atmospheric brightness temperatures at 23.8 and $31.4 \mathrm{GHz}$ derived from the radiosonde soundings collected in each March from the year 1988 to 1997 (Liou, 1999a), and (b) the corresponding PW and ZWD. Generally speaking, the more the PW, the higher the brightness temperature. In addition, brightness temperatures are higher for $23.8 \mathrm{GHz}$ than $31.4 \mathrm{GHz}$ because $23.8 \mathrm{GHz}$ is closer to 
Table 3. Regression coefficients for PW and ZWD for a 23.8 and $31.4 \mathrm{GHz}$ radiometer, and the corresponding rmsd ( $\mathrm{cm})$ about the associated regression.

\begin{tabular}{ccccccccc}
\hline Month & ZWD0 & ZWD1 & ZWD2 & rmsd & PW0 & PW1 & PW2 & rmsd \\
\hline Jan & -2.60 & 0.660 & -0.409 & 1.04 & -0.445 & 0.105 & -0.066 & 0.198 \\
Feb & -2.07 & 0.646 & -0.398 & 1.60 & -0.393 & 0.104 & -0.064 & 0.227 \\
Mar & -3.46 & 0.656 & -0.388 & 1.78 & -0.603 & 0.106 & -0.063 & 0.248 \\
Apr & -5.50 & 0.694 & -0.412 & 2.17 & -0.882 & 0.112 & -0.067 & 0.303 \\
May & -11.17 & 0.771 & -0.436 & 2.59 & -1.691 & 0.123 & -0.069 & 0.365 \\
Jun & -15.57 & 0.832 & -0.476 & 2.88 & -2.250 & 0.131 & -0.075 & 0.413 \\
Jul & -12.55 & 0.758 & -0.408 & 2.46 & -1.781 & 0.120 & -0.065 & 0.348 \\
Aug & -14.84 & 0.793 & -0.420 & 2.56 & -2.112 & 0.125 & -0.066 & 0.367 \\
Sep & -15.52 & 0.849 & -0.494 & 2.79 & -2.309 & 0.134 & -0.078 & 0.398 \\
Oct & -5.92 & 0.682 & -0.398 & 1.60 & -0.967 & 0.110 & -0.065 & 0.222 \\
Nov & -2.65 & 0.618 & -0.358 & 1.39 & -0.486 & 0.111 & -0.059 & 0.182 \\
Dec & -0.55 & 0.581 & -0.354 & 1.15 & -0.181 & 0.095 & -0.058 & 0.165 \\
\hline
\end{tabular}

Table 4. Radiosonde, GPS, and WVR observations of ZWD.

\begin{tabular}{ccc}
\hline Observations & Mean, cm & Standard Deviation, cm \\
\hline Radiosonde & 24.1 & 2.96 \\
GPS & 21.2 & 2.41 \\
WVR & 21.6 & 2.75 \\
GPS-WVR & -0.35 & 1.70 \\
\hline
\end{tabular}

Table 5. Radiosonde, GPS, and WVR observations of PW.

\begin{tabular}{ccc}
\hline Observations & Mean, cm & Standard Deviation, cm \\
\hline Radiosonde & 3.88 & 0.46 \\
GPS & 3.38 & 0.39 \\
WVR & 3.43 & 0.44 \\
GPS-WVR & -0.04 & 0.27 \\
\hline
\end{tabular}

the $22.235 \mathrm{GHz}$ water vapor absorption line. Figure 4(b) demonstrates that ZWD is proportional to PW. For simplicity of this presentation, we do not show results for the other months because their signatures of brightness temperatures, PW, and ZWD are similar to those shown for March except that the absolute values of their magnitudes differ from each other to some extent. After brightness temperatures at the two channels of interest are obtained, bilinear regression coefficients for the months of the year can be determined. The derived regression coefficients are listed in Table 3. It is evident that the coefficients are seasonally dependent so that March coefficients are used for further analysis.
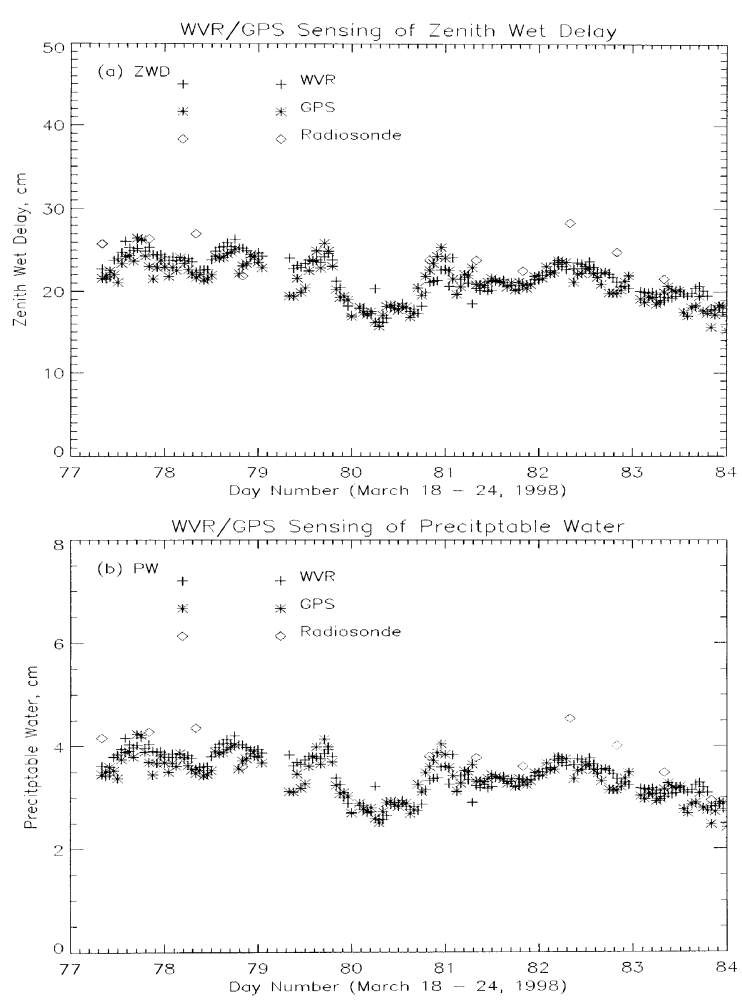

Fig. 5. GPS sensing of (a) ZWD and (b) PW versus their corresponding WVR and radiosonde observations at the Taipei weather station from March 18 to 24, 1998 .

\section{Experiment Description and Analysis of Results}

CWB's Taipei weather station is equipped with GPS dual frequency receivers, surface meteorological instruments, and radiosondes. Since radiosonde soundings are sparsely taken, a WVR was installed to increase the frequency of ZWD and PW measurements at the Taipei site from March 18 to 24, 1998. The WVR (model WVR-1100) operating at 23.8 and 
Table 6. Variability of GPS minus WVR versus GPS-observed PW.

\begin{tabular}{lcc}
\hline Authors & GPS-observed PW, cm & GPS-WVR PW, mm \\
\hline Rocken et al. (1993) & $\sim 1.0$ & 0.66 \\
Emardson et al. (1998) & $\sim 1.36$ & 1.50 \\
Rocken et al. (1997) & $\sim 1.4$ & 1.30 \\
Emardson et al. $(1998)$ & $\sim 1.49$ & 1.70 \\
Duan et al. (1996) & 1.5 & 1.26 \\
Tregoning et al. $(1998)$ & $\sim 1.5$ & 1.40 \\
Emardson et al. $(1998)$ & $\sim 1.93$ & 1.90 \\
Duan et al. (1996) & 2.1 & 1.15 \\
Rocken et al. (1995) & $\sim 2.1$ & 1.20 \\
Rocken et al. (1995) & $\sim 2.4$ & 1.39 \\
Duan et al. (1996) & 2.4 & 1.45 \\
Duan et al. (1996) & 2.6 & 1.30 \\
Rocken et al. (1995) & $\sim 2.6$ & 1.77 \\
Current Study & 3.38 & 2.70 \\
Heymsfield et al. (2000) & 4.38 & 2.23 \\
\hline
\end{tabular}

31.4 GHz was loaned by Radiometrics Corporation, USA (Radiometrics WVR-1100 Instrument Manual, 1997). ZWD and PW are derived from the observed microwave emission of the atmosphere through a bilinear regression method as explained in Section 3. The GPS data are utilized to estimate hourly ZWD at the Taipei station together with the baseline vector components from Tsukuba to Taipei. L1 and L2 carrier phase observations are used in data reduction, and the precise GPS ephemeris is obtained from the International GPS Service for Geodynamics (IGS). A satellite elevation cutoff angle of 12 degrees is used in the data processing.

Figure 5 compares (a) ZWD and (b) PW observed by WVR, GPS, and radiosondes for March 18 to 24, 1998. Generally speaking, observations from all of the three techniques match each other reasonably well except for the part where radiosonde observables appear to be somewhat higher than the other two as listed in Tables 4 and 5. Note that radiosonde soundings were collected twice daily, while GPS observations were taken two times per minute and WVR observations were taken once per couple of minutes. We therefore interpolated the GPS and WVR data to provide hourly observations. We found that the average difference between GPS and WVR measurements of ZWD is $-0.35 \mathrm{~cm}$ with a standard deviation of $1.70 \mathrm{~cm}$. The corresponding average difference in $\mathrm{PW}$ is $-0.04 \mathrm{~cm}$ with a standard deviation of $0.27 \mathrm{~cm}$. This result is considerably higher than 1-2 mm agreement reported by others at higher latitudes (e.g., Rocken et al., 1993, 1995, 1997; Duan et al., 1996; Emardson et al., 1998; Tregoning et al., 1998), roughly in proportion to the differences in PW. This suggests that the agreement between GPS- and WVR-sensed PW may be dependent on the total water vapor burden.

To examine the scaling of the disagreement between GPSand WVR-observed PW on the total water vapor burden, more extensive comparisons at various latitudes and humidity conditions should be explored. Table 6 lists GPS-observed PW and GPS- minus WVR-measured PW from various papers in the literature. The numbers followed by the approximation sign " " implies that they are estimated by eye from plots in the cited papers. The results show that a scaling of rms difference (rmsd) with the total water vapor burden (PW) exists, and, hence, a linear regression between them is determined. The derived linear regression is $\mathrm{rmsd}=0.413 \mathrm{PW}+$ 0.622 . The rms deviation about this regression is 0.346 .

\section{Conclusions}

GPS and WVR observations with surface meteorological measurements were utilized to derive ZWD and PW. Observations were made at CWB's Taipei weather station from March 18 to 24, 1998. To convert ZWD to PW for the GPS approach, the $T_{\mathrm{m}}-T_{\mathrm{s}}$ relationship was first derived based upon 10-year radiosonde data collected at CWB's Taipei weather station from the year 1988 to 1997 . Its dependence on season was demonstrated so that the March data were used to avoid seasonal effect on further analysis. The sensing of PW and ZWD by the two-channel WVR approach, and its bilinear regression coefficients are also determined using the same set of climatological data. $\Pi$ estimated from surface temperatures correlates by $85 \%$ with its calculation from radiosonde data. Average ZWD and PW estimates from the GPS data differ from the corresponding WVR observations by -0.35 and $-0.04 \mathrm{~cm}$, respectively, during the 1-week field experiment. Their means (standard deviations) are 21.2 (2.41) and $3.38(0.39) \mathrm{cm}$, respectively. These results, compared with those reported by others at higher latitudes, suggest that the agreement of GPS- and WVR-sensed PW scales with the total water vapor burden. This suggestion was justified by using more comparisons obtained from the cited papers. As 
a result, a linear regression relationship between the GPSminus WVR-observed PW (rmsd) and GPS-measured PW is obtained. It is rmsd $=0.413 \mathrm{PW}+0.622$ with an $\mathrm{rms}$ deviation of 0.346 about the regression.

Acknowledgments. This work was supported by grants from NSC89-2111-M-008-025 and NSC89-2212-E-008-006. The authors thank Radiometrics Corporation for the loan of WVR, and CWB for providing GPS data and a space to conduct the WVR experiment.

\section{References}

Bean, B. R. and E. J. Dutton, Radio Meteorology, 435 pp., Dover, New York, U.S.A., 1968.

Beutler, G., E. Brockman, S. Frankhauser, W. Gurtner, J. Johnson, L. Mervart, M. Rothacher, S. Schaer, T. Springer, and R. Weber, Bernese GPS Software Version 4.0, Univ. Of Berne, 418 pp., 1996.

Bevis, M., S. Businger, T. A. Herring, C. Rocken, R. A. Anthes, and R. H. Ware, GPS meteorology: Remote sensing of atmospheric water vapor using the global positioning system, J. Geophys. Res., 97, 15,784-15,801, 1992.

Bevis, M., S. Businger, S. Chiswell, T. A. Herring, R. A. Anthes, C. Rocken, and R. H. Ware, GPS meteorology: Mapping zenith wet delays onto precipitable water, J. Appl. Meteorol., 33, 379-386, 1994.

Businger, S., S. R. Chiswell, M. Bevis, J. Duan, R. A. Anthes, C. Rocken, R. H. Ware, M. Exner, T. Van Hove, and F. S. Solheim, The promise of GPS in atmospheric monitoring, Bull. Amer. Meteorol. Soc., 77, 5-18, 1996.

Duan, J., M. Bevis, P. Fang, Y. Bock, S. Chiswell, S. Businger, C. Rocken, F. Solheim, T. van Hove, R. Ware, S. McClusky, T. A. Herring, and R. W. Ware, GPS Meteorology: Direct estimation of the absolute value of precipitable water, J. Appl. Meteorol., 35, 830-838, 1996.

Emardson, T. R., G. Elgered, and J. Johansson, Three months of continuous monitoring of atmospheric water vapor with a network of GPS receivers,
J. Geophys. Res., 103, 1807-1820, 1998.

Heymsfield, A., B. Gandrud, G. McFarquhar, T. Van Hove, and R. Ware, GPS, WVR, and radiosonde measurements of precipitable water at a tropical Indian Ocean site, J. Oceanic Atmos. Technol., 2000 (in preparation)

Janssen, M. A., An introduction to the passive microwave remote sensing of atmospheres, in Atmospheric Remote Sensing by Microwave Radiometry, Edited by M. A. Janssen, 572 pp., John Wiley \& Sons, Inc., New York, U.S.A., 1993.

Liebe, H. J., MPM-An atmospheric millimeter wave propagation model, Int. J. Infrared Millimeter Waves, 10, 631-650, 1989.

Liou, Y.-A., Spatial variation in atmospheric wet delay observed by a groundbased, dual-channel radiometer, J. Photogrammetry and Remote Sensing, 4, 31-41, 1999a (in Chinese).

Liou, Y.-A., Ground-based radiometric sensing of atmospheric dynamics in precipitable water vapor, Atmospheric Sciences, 27, 141-158, 1999b (in Chinese).

Liou, Y.-A. and M. Yang, Precipitable water from GPS: A WVR constraint approach, Atmospheric Sciences, 27, 131-140, 1999 (in Chinese).

Radiometrics WVR-1100 Instrument Manual, WVR-1100 Water Vapor and Liquid Water Radiometer, 30 pp., June 12, 1997.

Rocken, C., R. Ware, T. Van Hove, F. Solheim, C. Alber, J. Johnson, M. Bevis, and S. Businger, Sensing atmospheric water vapor with the Global Positioning System, Geophys. Res. Lett., 20, 2631-2634, 1993.

Rocken, C., T. Van Hove, J. Johnson, F. Solheim, R. Ware, M. Bevis, S. Businger, S. Chiswell, GPS Storm-GPS Sensing of atmospheric water vapor for meteorology, J. Oceanic Atmos. Technol., 12, 468-478, 1995.

Rocken, C., T. Van Hove, and R. Ware, Near real-time GPS sensing of atmospheric water vapor, Geophys. Res. Lett., 24, 3221-3224, 1997.

Tregoning, P., R. Boers, D. O'Brien, and M. Hendy, Accuracy of absolute precipitable water vapor estimates from GPS observations, J. Geophys. Res., 103, 28,701-28,710, 1998 .

Ware, R., C. Alber, C. Rocken, and F. Solheim, Sensing integrated water vapor along GPS paths, Geophys. Res. Lett., 24, 3583-3586, 1997.

Y.-A. Liou (e-mail: yueian@csrsr.ncu.edu.tw), C.-Y. Huang, and Y.-T. Teng 